\title{
RAZÕES PARA A PARTICIPAÇÃO NA IMPLEMENTAÇÃO DO IPTU PROGRESSIVO NO TEMPO À LUZ DO AGIR COMUNICATIVO
}

\section{Mozart Victor Ramos Silveira ${ }^{1}$}

RESUMO: O presente artigo trata da questão do planejamento urbano sobre o viés participativo, com ênfase no o IPTU progressivo no tempo. Para isso, apresenta-se a teoria de base, o agir comunicativo de Habermas e os seus conceitos fundamentais. Após isso, trabalhase com o marco jurídico legislativo do âmbito federal ao municipal de Belém. Por fím, analisa-se questões relacionadas à participação, e a sua importância na elaboração de políticas públicas urbanísticas, em especial, para os fins desse artigo. Os resultados mostram a importância da participação como meio para solução de complexas questões que afetam a vida de todos os cidadãos.

Palavras-chave: IPTU progressivo no tempo; planejamento urbano; agir comunicativo; participação; Belém.

\section{REASONS FOR PARTICIPATION IN THE IMPLEMENTATION OF PROGRESSIVE TAX OVER TIME IN THE LIGHT OF COMMUNICATIVE ACTION THEORY}

\begin{abstract}
This paper deals with the issue of participatory urban planning, with emphasis on the progressive property tax over time. Besides that, we present Habermas's basic theory, communicative acting and its fundamental concepts. After that, we work with the legal framework of the federal scope to the municipal of Belém. Finally, we analyze issues related to participation, and its importance in the development of urban public policies, especially for the purposes of this article. The results show the importance of participation as a means of solving complex issues that affect the lives of all citizens.
\end{abstract}

Keywords: Progressive territorial tax over time; urban planning; communicative action; participation; Belém.

\section{INTRODUÇÃO:}

A análise do direito urbano não se trata de estudar apenas indivíduos. Eles são importantes, uma vez que eles são fundamentais, dado que eles são (ou deveriam ser) os responsáveis pelos rumos e decisões políticos tomados. Todavia, analisa-se mais do que os indivíduos per se, estuda-se movimentos. Movimentos históricos de massa nas quais as pessoas estão refletindo e interagindo neles. Estamos falando de histórias que precisam de um

\footnotetext{
${ }^{1}$ Doutorando na linha de pesquisa Sociedade, Urbanização e Estudos Populacionais de Pós-Graduação em Desenvolvimento Sustentável do Trópico Úmido no Núcleo de Altos Estudos Amazônicos da UFPA; Mestre Planejamento do Desenvolvimento (PPGDSTU/NAEA/UFPA); Especialista em Direito Tributário, pela UNIDERP (2012); e Bacharel em Direito (UFPA). Oficial de Justiça Avaliador. E-mail: mozart.silveira@ yahoo.com.br
} 
narrador que entenda o Geist ${ }^{2}$ dos indivíduos que estão no mundo da vida. Esse narrador também é responsável por nos explicar o que está acontecendo, para que possamos melhor entender os comportamentos das personagens. Podemos citar diversos pensadores que se preocuparam em entender esses movimentos: Wittgenstein, Russel, Einstein. Existem muitas questões epistemológicas a serem entendidas para se entender os movimentos históricos. Todavia, houve uma real revolução no pensamento e no imaginário coletivo quando Nietzsche disse: "Gott ist tot! Gott bleibt tot! Und wir haben ihn getötet! Wie trösten wir uns, die Mörder aller Mörder? Das Heiligste und Mächtigste, was die Welt bisher besaß, es ist unter unseren Messern verblutet" (NIETZSCHE, p. 120, 2012).

Ao proferir: "Deus está morto", ele próprio não fez muito mais que escrever palavras em sua língua. Mas o sentido dessas palavras revela a revolução que o mundo estava sofrendo. Ele mostrou a incerteza e o medo de viver em um mundo no qual as regras universais não são regidas por divindades. O que ele mostrou foi a angústia de viver em um mundo após revoluções científicas, após Copérnico, Galileu, Pasteur e Freud. Ou seja, um universo no qual ser humano significa ter também a responsabilidade por nossas ações, descobertas, guerras e miséria. No qual o narrador não é mais uma divindade, que controla o universo.

Desse modo, é preciso entender o mundo em que vivemos, em escala global ou local (em especial para esse artigo as cidades). E nesse ponto, o direito urbano ganha destaque. Ao se trabalhar com o planejamento urbano, temos diversas questões a serem resolvidas. E, em muitos casos, quem toma essas decisões não são os mais fortemente afetados por elas. Buscando trabalhar essas questões na problemática urbana, o objetivo do presente artigo é apresentar razões e reflexões para a necessidade de maior participação popular na tomada de decisões do planejamento urbano, em especial do IPTU progressivo no tempo (IPTUPT) em Belém, na região amazônica, seus benefícios e possibilidades.

Para esse fim, utiliza-se como base a teoria do agir comunicativo (HABERMAS, 2016), que nos mostra a necessidade de aumento de participação popular na tomada de decisões relacionadas ao planejamento urbano. Como metodologia, será buscada a análise através do materialismo histórico dialético, com cunho pós-marxista, por alguns também

\footnotetext{
${ }^{2}$ Não encontro tradução específica para o termo em português, aqui o termo está no sentido de fluxo de pensamentos.

${ }^{3}$ Tradução livre: "Deus está morto! Deus está morto! E nós o matamos! Como nos consolamos, os assassinos de todos os assassinos? A coisa mais sagrada e poderosa que o mundo já conheceu sangrou até a morte entre nossas facas".
} 
chamado de neomarxista, com ênfase nos métodos críticos desenvolvidos na escola de Frankfurt (THERBORN, 2012). Ainda quanto à parte metodológica, adota-se a hipótese de que a participação popular nas tomadas de decisão no planejamento urbano é essencial tanto epistemologicamente quanto em termos práticos.

\section{O CONCEITO "MUNDO DA VIDA" E O IDEALISMO DA SOCIOLOGIA HERMENÊUTICA COMO PRESSUPOSTOS PARA ELABORAÇÃO DE POLÍTICAS PÚBLICAS}

"Mundo da vida" (Lenemswelt) não é uma criação exclusiva de Habermas, contudo, em relação à interpretação sociológica de Habermas, o entendimento vigente sobre o Lebenswelt é refinado. Trata-se de um pressuposto para o agir comunicativo. Inicialmente, para se entender o conceito, Habermas diz que o mundo da vida se relaciona com três mundos que os sujeitos tomam de base para suas definições comuns, nos quais os indivíduos agem tomados pelo conhecimento (HABERMAS, 2016).

Por influência de escolas linguísticas, a sua teoria pressupõe que, na análise dos modos de utilização da linguagem, pode-se esclarecer o significado para um falante, no qual essas relações terão relações pragmáticas com: a) algo no mundo objetivo (entidades nas quais são possíveis enunciados verdadeiros); b) algo no mundo social (relações interpessoais); c) algo no mundo subjetivo (vivências do falante).

Tanto falantes quanto ouvintes utilizam o sistema de referência dos três mundos pra moldarem as suas significações. Daí, podemos ter "entendimento" (Verständigung), ou seja, a união dos participantes sobrea validade do que foi exteriorizado, ou "consenso" (Einverständnis), que é o reconhecimento intersubjetivo da pretensão de validade do falante (HABERMAS, 2016). Nesse contexto, se algumas premissas básicas não forem respeitadas, como a veracidade (ou a dúvida quanto à veracidade), adequação normativa à manifestação, racionalidade, não teremos um consenso na perspectiva de Habermas, mas sim um dissenso.

Em termos mais objetivos, podemos dizer que o mundo da vida é o espaço da razão comunicativa. Ele é constituído pela cultura, sociedade e personalidade, e se expressa pela busca do consenso (Einverständnis) entre os indivíduos, por intermédio do diálogo. O mundo da vida contrapõe-se ao mundo dos sistemas, onde predomina a razão instrumental, razão que se expressa em mecanismos funcionais que são construídos em torno do poder e do dinheiro. Eles coordenam as ações humanas garantindo a reprodução do mundo material. Esse mundo é 
o espaço do trabalho, da técnica, da economia. O sistema, por sua vez, possui dois (principais) subsistemas: o Estado e o mercado.

Desse modo, o agir orientado pelo entendimento possui o pressuposto de que os particulares realizem os seus planos de comum acordo, com uma situação definida consensualmente. O objetivo é evitar dois fracassos: o fracasso de entendimento (malentendido) e o risco do malogro do plano da ação (insucesso).

No mundo da vida racionalizado ${ }^{4}$, os conflitos surgiriam em seu próprio nome não havendo engodos por convicções outras ausentes do discurso. A ousada e vanguardista proposta do autor germânico é entendida como um norte, por isso mesmo ele dá especial atenção à função da educação, uma "pedagogização" dos processos de educação, livrando-a de imperativos eclesiásticos e familiares. Esse modelo libertário de educação não significa apenas uma formalização da formação profissional, mas uma ruptura na reflexão da reprodução simbólica do mundo da vida, e fundamenta as regras do jogo para como se deve elaborar políticas públicas baseadas em consensos, ouvindo-se todos e baseando-as no melhor argumento.

Contudo, no mundo pós-revoluções iluministas (Aufklärung), a modernidade se modernizou em diversas direções, causando às populações perda de sentidos, anomia e alienação, patologias da sociedade burguesa apresentadas em Marx, o que leva a uma racionalização do mundo da vida. Por isso, Habermas entende que uma teoria social deve evoluir das premissas marxianas capaz de focalizar no mundo da vida, e que não seja totalizadora no que diz respeito à sociedade ou que a reduza a simples relações sistêmicas. "Portanto, a perspectiva da teoria dos sistemas é relativizada pela ideia de que a racionalização do mundo da vida provoca uma variação dos padrões estruturais que definem a manutenção do sistema" (HABERMAS, 2016, p. 269).

Em suma, a concepção de sociedade como mundo da vida necessita adotar três ficções: a autonomia dos agentes, a independência da cultura e a transparência da comunicação. Esses pressupostos são fundamentais para a elaboração de quaisquer projetos ou tentativas de políticas públicas, como IPTUPT, que possuem, no campo do discurso, um caráter voltado à autonomia e emancipação de camadas populares que sofrem dificuldades diversas no parâmetro da função social da propriedade que emana do sistema.

\footnotetext{
${ }^{4}$ Entendido como um estágio final da evolução das concepções de democracia radical habermasiana.
} 


\section{DISJUNÇÃO ENTRE MUNDO DA VIDA E SISTEMA:}

Habermas nos diz que Parsons entende que o conceito de mundo da vida deve ser obtido a partir de uma teoria da ação, que seria o entorno sistêmico. Nesse sentido, o mundo da vida seria um sistema parcial de um "sistema geral da ação", o que inclui o substrato físico do mundo da vida. Além disso, na perspectiva do autor, a sociologia orientada pela teoria de sistemas refere-se a apenas um dos três componentes do mundo da vida: sistema de instituições em relação ao qual a cultura e personalidade formariam um simples entorno. Isso ocorre por razões metodológicas. Habermas entende que há mais de uma perspectiva para que se possa observar a evolução da sociedade, ele entende que é possível observar a evolução social pelo mundo da vida, que não é orientado por um meio sistêmico (HABERMAS, 2016).

Do ponto de vista do mundo da vida, os sistemas aparecem como uma parte da sociedade retificada, e evolução significa um processo de racionalização, que pode ser concebido como uma liberação progressiva do potencial de racionalidade que a ação comunicativa leva.

Weber entende que a legitimidade do poder que caracteriza as sociedades modernas é a legal ou racional, com fundamento no cumprimento de regras feitas pela burocracia, independente do conteúdo dessas normas (WEBER, 1998). Contudo, após o holocausto nazista, não se pode mais fundamentar a legitimidade do poder na mera forma jurídica ou mesmo em doutrinas metafísicas ou religiosas.

Habermas reinterpreta a visão de Weber sobre o caráter contraditório e patológico de evolução da sociedade moderna. Ele chamou de "colonização do mundo da vida" o fenômeno em que, à medida que as economias domésticas, os trabalhadores e consumidores são submetidos aos imperativos do sistema econômico, são direcionados a um estilo de vida marcado por um utilitarismo centrado em torno da especialização. O sistema (ciência, economia, política, famílias e Estado) se apropria dos processos de cultura, sociedade e personalidade, ou seja, o mundo da vida (HABERMAS, 2016).

Utilizando-se a definição do nível evolutivo a partir das análises de Kohlberg, a separação total entre direito e moral só seria possível no que ele denominou de nível "pósconvencional", em que há ajuste entre normas e princípios ${ }^{5}$. Essa evolução é parte da estrutura do mundo da vida. Com essa independência do direito, tem-se origem um sistema

\footnotetext{
${ }^{5}$ Para um melhor entendimento do que a dogmática alemã interpreta da diferenciação entre princípios e regras, entendimento este adotado no direito brasileiro, vide ALEXY, R. Teoria dos direitos fundamentais. São Paulo: Malheiros, 2011.
}

Revista de Direito Urbanístico, Cidade e Alteridade | e-ISSN: 2525-989X | Belém | v. 5 | n. 2 | 
institucional que garante cada vez mais a legitimação dos procedimentos formais de criação e justificação de normas. Esse nível de desenvolvimento leva um desacoplamento às sociedades modernas, que significa uma diferenciação entre diversos tipos de condições da ação, que se formam através do consenso livre dos participantes.

Nesse contexto da evolução social, ele demonstra como se aplica a evolução de sua teoria do mundo da vida, na aplicação em sociedades de diversos estágios civilizatórios, mas sempre valorizando suas idiossincrasias e cosmovisões (Weltansicht). Nas sociedades organizadas na forma de Estado, a troca e o poder não podem mais se apoiar na troca de mulheres, regras de casamento, nem outros modos de trocas utilizados por civilizações em estágios evolutivos anteriores, utilizando-se a linguagem de Durkheim. Agora são necessárias duas grandezas abstratas: um poder de organização e um meio de controle. É nesse estágio civilizatório que o conceito de autoridade do cargo adquire pleno sentido. O soberano e os políticos possuem prerrogativas do mando e gozam desses poderes tanto na esfera pública quanto privada, interpretando-se como se ambas fossem um amálgama.

É nesse plano que o direito formal se torna uma garantia para a previsibilidade das relações comerciais. Quanto mais complexos os sistemas da sociedade se tornam, mais provincianos tornam-se os mundos da vida. Ele se encolhe até o ponto de se tornar um subsistema. O direito se especializa cada vez mais, tentando atingir todos os âmbitos da sociedade. Nesse sentido, o direito possui um papel ambíguo: ao mesmo tempo em que pode ser instrumento de colonização do mundo da vida, também pode ser um meio de codificação de garantias.

Nessa codificação de garantias, a legitimidade do Estado e da própria ordem jurídica deve ser amparada em duas ideias fundamentais: democracia e respeito aos direitos humanos. Embora nenhuma das duas ideias se confunda com dignidade humana, as duas possuem embasamento semelhante à dignidade da pessoa humana: as pessoas devem ser respeitadas como iguais e tratadas como sujeitos, não como meros objetos (SARMENTO, 2016).

Por esse motivo, não possui legitimidade o Estado autoritário ou totalitário, no qual o governo não se fundamente no consentimento dos governados e no qual ocorre sistemática violação de direitos básicos e institucionalmente a degradação das pessoas.

\section{PACTO FEDERATIVO E IMPOSTOS}


Por força do pacto federativo, o Brasil é um Estado Federal, isso significa que temos um acordo de base territorial pelo meio do qual grupos localizados em diversas partes de um determinado território se organizam em busca de harmonia entre suas demandas próprias e interesses gerais da sociedade que se pretende construir, isso tudo, claro, no âmbito jurídico positivo. Ou seja, o pacto federativo é um formato político-institucional cujo objetivo é preservar a diversidade, unificando e conciliando metas, por vezes, opostos (CASTRO, 2014). Nesse sentido, o sistema jurídico brasileiro é baseado em modelos que possuem normas positivadas em um conjunto de regras dispostas hierarquicamente. Existe uma gradação entre as normas inferiores e que podem ser criadas pelos particulares, os contratos, até as normas de cúpula que são as da Constituição da República Federativa do Brasil. Nesse sistema, em que as leis de piso buscam a sua validação na norma hierarquicamente superior, temos o que se convencionou chamar de pirâmide jurídica. Nas palavras de Kelsen "o fundamento de validade de uma norma apenas pode ser a validade de uma outra norma" (KELSEN, 1962, p. 2).

Dessa forma, todas as leis do direito pátrio devem obediência à Constituição da República Federativa do Brasil. Consta no art. $1^{\circ}$ da Carta Magna que o país é uma república (BRASIL, 2018). Esse conceito jurídico posto possui inúmeras implicações, mas, para os fins do presente artigo, o entendimento adotado é o de que, nessa forma, o Estado não é o detentor de todos os poderes e direitos do cidadão. Na realidade, a sua função primordial é a de ser um garantidor dos interesses morais e materiais dos seus subordinados. Então, a concepção que se tem de República é "o tipo de governo, fundado na igualdade formal das pessoas, em que os detentores do poder político exercem-no em caráter eletivo, representativo (de regra), transitório e com responsabilidade" (CARRAZZA, 2004, p. 48). Aqui, deve-se informar os conceitos relacionados a direito e a sua natureza. Kelsen apresenta diferenciações entre o que se entende pelo "ser" e o "dever-ser". Inicialmente, temos uma distinção epistemológica, onde há, de fato, distinção entre descrição e avaliação. Para o autor, o direito deveria ser estudado pelo viés positivo, não tratando de como ele se dá no mundo dos fatos, mas um estudo de um ponto de vista objetivo e neutro da norma, sem as influências da moral ou outros fatores externos (KELSEN, 1962). Kelsen entende que o direito, enquanto conjunto de normas é pertencente ao "dever-ser", todavia, no estudo do direito orientado pela teoria pura por ele proposta, o estudo a ser feito é com o fático, ou seja, como ele é, e não como deve ser (KELSEN, 1962). 
A teoria de Kelsen, ainda que extremamente relevante, não passou incólume a críticas. Bobbio afirma que a corrente positivista jurídica, "nasce do impulso histórico para a legislação, se realiza quando a lei se torna a fonte exclusiva - ou, de qualquer modo, absolutamente prevalente - do direito, e seu resultado último é apresentado pela codificação" (BOBBIO, 1995, p. 119). Nesse paradigma positivista, o direito deixou o seu papel operacional de qualificar condutas, assumindo um papel técnico instrumental de gestão da sociedade, ou seja, proibindo, permitindo, estimulando e desestimulando comportamentos. As consequências da primazia da legalidade positivista trouxeram outros aspectos fundamentais para a análise dos limites da racionalidade. Esses aspectos não apresentam erros no positivismo jurídico como ciência, mas erros na sua aplicabilidade, relacionados com a lógica do razoável. Em que pese à realidade contraditória, a República não deve servir como favorecimento a apenas alguns setores da sociedade, uma vez que a base do poder republicano é a igualdade política entre os homens. Desse modo, deve-se sempre buscar o bem coletivo no governo republicano, e não a manutenção de privilégios das classes dominantes. Essa lição é especialmente forte para o Poder Legislativo, que possui maior liberdade criativa em relação ao Poder Executivo que, na clássica divisão de poderes, limitar-se-ia a aplicar as regras.

Outro conceito fundamental que deve ser explicado é o de direitos fundamentais, que tem relação com direitos humanos. Apesar de não ser unânime, a classificação mais adotada é a que entende direitos fundamentais, são os direitos humanos, reconhecidos no âmbito interno, reconhecidos e protegidos com status de direito constitucional. É importante essa distinção, pois a dignidade humana é exatamente um dos fundamentos da república (BRASIL, 2018), e esse direito fundamental deve ser observado na análise do princípio republicano. E como o direito não pode se distanciar das premissas básicas da Constituição Federal, dado o seu valor axiológico, algumas premissas acerca desse importante princípio merecem ser apresentadas. Então, toda a análise do princípio republicano passa pelo entendimento da dignidade humana como fundamento da República. Ambos são importantíssimos, não podem ser ignorados em qualquer aplicação hermenêutica.

\section{O PRINCÍPIO REPUBLICANO E A CAPACIDADE CONTRIBUTIVA:}

Inicialmente, é preciso delimitar conceitualmente princípios, e diferenciá-los das regras. A semelhança é que ambos são normas, uma vez que entram no campo do "dever ser". Desse modo, a distinção apontada é: as regras podem ser cumpridas ou não, e os princípios 
ordenam que algo seja realizado na maior medida possível dentro das possibilidades jurídicas e fáticas (ALEXY, 2011).

Em outras palavras, enquanto às regras ou elas são aplicadas integralmente ou não são aplicadas, aos princípios tem-se uma margem maior para ponderação. A título de exemplo, uma regra pode ser: "é proibido fumar no avião", ou seja, não existe margem de apreciação. Um exemplo de princípio seria o da igualdade, no qual podem ser feitos questionamentos quanto à igualdade formal, material, econômica, dentre outros parâmetros. Nesse sentido, por força do princípio republicano, deve-se afastar qualquer interpretação que permita às normas tributárias serem editadas com o viés de proveito às classes dominantes, conforme expressa determinação da Constituição da República Federativa do Brasil, em seu artigo $5^{\circ}$, que trata da igualdade perante a lei (BRASIL, 2018).

Sob a ótica constitucional, os tributos não podem ter outro fim além de instrumentar o Estado a alcançar o interesse público. Juridicamente falando, é necessário delimitar o que se entende por interesse público. Não é simplesmente um conceito antagônico ao de interesse privado. $\mathrm{Na}$ verdade, é o "interesse resultante do conjunto de interesses que os indivíduos pessoalmente têm quando considerados em sua qualidade de membros da sociedade e pelo simples fato de o serem" (MELLO, 2009, p. 61). Qualquer interpretação que não persiga essa finalidade deve ser dada como inconstitucional.

O princípio republicano exige que todos que realizarem determinado fato, chamado pelos teóricos de fato imponível tributário, devem ser tributados igualitariamente. De todo modo, é inteiramente coerente, além de reforçar o princípio republicano a aplicação da regra da capacidade contributiva, expresso no art. $145, \S 1^{\circ}$ da Constituição da República Federativa do Brasil. Então, resta inequívoca a interpretação de que há uma correlação entre os impostos e a capacidade contributiva. De maneira coerente com o sistema, é lógico e jurídico interpretar-se que, em termos econômicos, quem possua mais capacidade de pagar, pague mais, proporcionalmente, do que quem possua menos capacidade contributiva. O referido princípio guia a tributação por meio de impostos. Existe íntima ligação desse princípio para com o princípio da igualdade, motivo pelo qual é conhecido como um dos mais eficazes mecanismos para se alcançar a justiça fiscal (TIPKE, 1994).

Os impostos, se ajustados à capacidade contributiva, permitem que os cidadãos possam cumprir os seus deveres tributários, em demonstração de solidariedade política, econômica e social. O pagamento dos tributos deve contribuir para o custeio da máquina 
pública não em razão do que receberam do Estado, mas sim de suas potencialidades econômicas. Essa é a razão pela qual, no ordenamento jurídico pátrio, todos os impostos devem, sempre que possível, ser progressivos, para fins de se atender ao disposto no princípio da capacidade contributiva, ainda que a Constituição Federal tenha expressamente determinado apenas a progressividade ao Imposto de Renda e ao Imposto Predial e Territorial Urbano (IPTU), nos artigos 153, $\S 2^{\circ}$, I e $156, \S 1^{\circ}$ (BRASIL, 2018).

Isso se dá porque a progressividade tributária é a uma excelente forma de se afastar, no campo dos impostos, as injustiças tributárias, vedadas constitucionalmente. Quando se deixa de aplicar o referido princípio, ceifa-se qualquer tentativa de igualdade tributária (CARRAZZA, 2004). Por isso, exceto quando a própria norma da Carta Magna assim o fizer, os impostos com alíquota fixa são inconstitucionais, por contrariar o princípio da capacidade contributiva, que exige que a tributação se dê de acordo com as manifestações de riqueza do contribuinte.

A capacidade contributiva elencada pela Constituição da República Federativa do Brasil que obriga o legislativo é do tipo objetiva, pois se refere não às condições econômicas reais de cada contribuinte de maneira individualizada, mas sim às manifestações objetivas de riqueza, como, por exemplo, ter um imóvel, um veículo automotor. Percebe-se, então, que o princípio possui como destinatário o próprio legislador. Impostos, para que sejam cobrados, precisam seguir regras e, para os fins do artigo, é importante apresentar os conceitos de hipótese de incidência e base de cálculo. Becker, informa que a base de cálculo é como o núcleo da norma tributária. Ela confere o gênero jurídico ao tributo, e os demais elementos da norma tributária lhe são adjetivos (BECKER 2002). Para melhor o entendimento, tomemos como base na norma positivada do Código Tributário Nacional (CTN), acerca do IPTU: Art. 32. O imposto, de competência dos Municípios, sobre a propriedade predial e
territorial urbana tem como fato gerador a propriedade, o domínio útil ou a posse de
bem imóvel por natureza ou por acessão física, como definido na lei civil, localizado
na zona urbana do Município.
Art. 33. A base do cálculo do imposto é o valor venal do imóvel. (BRASIL, 2018, p.
681)

Nesse exemplo normativo, o fato gerador do imposto territorial urbano é ser proprietário de bem imóvel, ao passo que a sua base de cálculo é o valor venal do referido imóvel, que é definido pelo Fisco. Fica claro, então, que o IPTU deve obediência ao princípio da capacidade contributiva. É preciso notar que a capacidade contributiva, no que se refere à 
tributação do IPTU, é aferida pelo próprio imóvel, e não pelos bens e valores que o proprietário eventualmente tenha.

\section{O DIREITO À PARTICIPAÇÃO NO PLANEJAMENTO URBANO NA SISTEMÁTICA CONSTITUCIONAL DO IPTUPT EM BELÉM:}

A cidade é anterior à industrialização, mas a industrialização é responsável por caracterizar a sociedade contemporânea. As cidades, no passado, apoiaram comunidades de camponeses e auxiliaram na libertação desses. Os benefícios dos centros urbanos, locais de vida social e política acumulam não apenas riquezas in natura, mas também conhecimentos, técnicas e obras de arte e monumentos (LEFEBVRE, 2001).

"O ar da cidade liberta”, já se afirmou. E essa ideia ganhou força com a saída dos servos dos campos medievais para a cidade, nas quais podiam reivindicar liberdades pessoais e políticas que eram mais amplas no ambiente urbano. Dessa associação da vida citadina e as liberdades pessoais, que incluem explorar, criar, e definir novos modos de vida, tem longas histórias, uma vez que diversos migrantes têm buscado as cidades como ambiente seguro das repressões rurais (HARVEY, 2013). "A cidade aparece, então, como uma semente de liberdade; gera produções históricas e sociais que contribuem para o desmantelamento do feudalismo" (SANTOS, 2014, p. 59). Com isso, tivemos diversas mudanças. Regiões perdem população e outras crescem, tornam-se mais dinâmicas. Mas, o ponto fulcral desse movimento se deve à urbanização. E, analisando o fenômeno, a difusão de grandes cidades se deu de maneira surpreendente nos países pobres. É claro que a urbanização cria diversas novas dinâmicas, ocasionando novos problemas a serem lidados. Isso tudo se soma ao fato de, atualmente, vivermos em tempos em que os ideais de direitos humanos têm primazia do ponto de vista político e ético. Nesse sentido, pode-se entender que o tipo de cidade que queremos depende do tipo de pessoa, relações sociais e com a natureza que buscamos. O direito à cidade é muito mais que o simples direito a acessos individuais ou coletivos incorporados à cidade, é um direito de mudar e reinventar a cidade conforme nossos desejos (HARVEY, 2014).

$\mathrm{O}$ direito à cidade, que

[...] se manifesta como forma superior dos direitos: direito à liberdade, à individualização na socialização, ao habitat e ao habitar. $\mathrm{O}$ direito à obra (atividade participante) e o direito à apropriação (bem distinto do direito à propriedade) estão implicados no direito à cidade. (LEFEBVRE, 2001, p. 134). 
O direito à cidade significa o direito de todos de criar cidades que satisfaçam as necessidades humanas. Não se trata de um direito de ter o que sobra dos detentores dos meios de produção. É um direito inerente a todos de construir diferentes tipos de cidade, valorizando as subjetividades. Não é simplesmente o direito a utilizar o que já existe na cidade (HARVEY, 2009). Um elemento essencial ao direito à cidade é o direito à participação. O que significa o direito de todos os habitantes de participarem plenamente das muitas oportunidades que a cidade oferece. É uma preocupação com a exclusão de camadas populacionais dessas oportunidades. A demanda por participação se apresenta por mais de um aspecto. De um lado, busca-se uma cidade mais inclusiva, na qual oportunidades sejam apresentadas amplamente à população. Por outro lado, a participação deve ter necessariamente um componente político. Envolve a inclusão nos processos decisórios, com direito à voz significativa em todas as decisões relacionadas com o espaço urbano. A consequência dessa falta de poder decisório é a criação de situações nas qual a camada mais abastada da sociedade exerce o domínio sobre a cidade, como forma de utilizar o seu excedente de capital. Desse modo, a luta pelo direito à cidade é também uma luta contra o próprio sistema, que coloniza o mundo da vida.

Entretanto, a participação popular requer muito mais que simplesmente dizer que a população vai participar por meio de leis. Uma problemática básica é a de como criar uma atmosfera para o planejamento e tomada de decisões. Para esse obstáculo, devemos antes solucionar quatro questões que devem ser deixadas explícitas: a) Porque precisamos mudar? Para que seja possível a participação, deve-se entender que as políticas públicas, como o IPTUPT, irão afetar toda a sociedade, e deve-se tratar desses riscos de maneira adequada. b) $O$ que eu ganho com isso? Os cidadãos precisam compreender o que ocorre no planejamento urbano causam benefícios ou prejuízos a eles próprios. c) Isso limita as minhas opiniões? Pessoas tendem a negar posições impostas. Essa perda de soberania e apercepção de dominação é uma armadilha para diminuição da autonomia. d) Eu me sinto pessoalmente envolvido? Mudanças geralmente afetam os modos de vida (SCHWEIZER, P-J., et al, 2012). Se é algo externo às minhas proximidades, ou visto como algo aparentemente muito distante, como o IPTUPT, isso tende a afastar as pessoas da discussão.

É inegável que os habitantes exercem um papel considerável na produção da cidade como um produto coletivo, por meio de suas rotinas no convívio com a cidade. Mas a participação, no sentido buscado, reivindica o direito de participar das decisões de cúpula que moldam a cidade. Essas decisões, sem dúvidas, abrangem o planejamento urbano, opções de 
investimentos, escolhas de atores sociais que impactarão no dia a dia de todos. E os habitantes devem ocupar um lugar central dessas decisões. (LEFEBVRE, 2001). No atual sistema, as elites do capital e do governo controlam a produção do espaço urbano, e aos cidadãos possuem um distante papel marginal nas nessas decisões. Esse modo de produção põe em xeque o direito à cidade e o próprio estado democrático de direito. Esses direitos (fundamentais) empiricamente não representam o mundo da vida de parte dos cidadãos, e a situação é mais patente no ponto de vista do morador de metrópoles com demografias inchadas e precariedade de serviços, como é o caso de Belém, no estado do Pará. Por se tratarem de direitos constitucionais, encontrar mecanismos no próprio sistema podem gerar bons frutos, maiores aberturas cognitivas e menor subserviência do Lebenswelt. Dentre as possibilidades postas, está o IPTUPT.

Conforme falado alhures, o IPTU, ele deve obedecer ao princípio da capacidade contributiva, nos termos do art. $145, \S 1^{\circ}$ da Constituição Federal. E, por isso, deve ser progressivo. Trata-se de uma progressividade fiscal obrigatória. Nem um pouco obstante, existe outra progressividade no IPTU, chamada de extrafiscal. Em relação ao planejamento e gestão urbanos, é mais importante o estudo dessa segunda finalidade, ou seja, a capacidade de permitir que outros objetivos além da arrecadação pura e simplesmente sejam alcançados. Essas outras finalidades podem ser o desestímulo de práticas nocivas ao interesse coletivo, que possui proteção constitucional por meio do princípio da função social da propriedade, ou mesmo na promoção e distribuição indireta de renda (SOUZA, 2010). Nesse sentido, pode-se, sem embargo, afirmar que o ideário de direito à cidade pode ser buscado pela extrafiscalidade, sendo coerente com o interesse público por meio desses instrumentos. Assim, o art. 156, $\S 1^{\circ}$ da Carta Magna estabelece que o IPTU, além de dever obediência ao princípio da capacidade contributiva, terá alíquotas diferentes conforme a localização e o uso do imóvel. Importante a ressalva, essas disposições extrafiscais do imposto nada tem a ver com o princípio da capacidade contributiva. Ambos os princípios devem ser observados por convivência harmônica entre os artigos $145, \S 1^{\circ}$ e o art. 156, $\S 1^{\circ}$ da Constituição da República Federativa do Brasil.

Poucos instrumentos são tão necessários ao desenvolvimento urbano quanto o IPTU progressivo no tempo. Sua aplicação pode colaborar de maneira eficaz para imprimir maior justiça social às cidades. Conforme o art. $182, \S 4^{\circ}$ da Constituição Federal, é facultado ao poder público municipal, por meio de lei específica para área incluída no plano diretor, exigir, 
de acordo com lei federal, do proprietário do solo urbano não edificado, subutilizado ou não utilizado, que promova o seu adequado aproveitamento. Caso o particular não atenda à exigência do poder público, o dispositivo legal prevê providências a serem adotadas e, dentre elas, temos o IPTUPT.

A lei federal que regula o IPTU progressivo no tempo é o Estatuto da Cidade, Lei 10.257/2001, a qual prevê como consequência para o descumprimento das condições e prazos para o parcelamento, edificação ou utilização compulsória a aplicação do IPTU progressivo no tempo pelo prazo de cinco anos consecutivos (BRASIL, 2018). Lei municipal determinará a alíquota do IPTU aplicável a cada ano. É necessária certa atenção à norma. A alíquota não pode exceder duas vezes o valor referente ao ano anterior e deve-se respeitar a alíquota máxima de $15 \%$, conforme o art. $7^{\circ}, \S 1^{\circ}$ do Estatuto da Cidade. Por fim, para evitar a frustração de objetivos constitucionais por benefícios fiscais, o $\S 3^{\circ}$ do artigo em questão veda que se conceda isenções e anistias relativas ao IPTU progressivo no tempo. Além disso, caso não haja o pagamento do IPTU progressivo no tempo, pode-se adotar medidas mais drásticas, como a desapropriação do imóvel. Então, o IPTU terá alíquotas diferentes de acordo com a localização e o uso do imóvel, para assegurar o cumprimento da função social da propriedade. Função social é um termo que deve ser definido nos planos diretores de cada município. No caso do plano diretor do município de Belém, a função social é assim delimitada:

Art. $3^{\circ}$ São princípios fundamentais para a execução da política urbana do Município de Belém:

I - função social da cidade, que compreende os direitos à terra urbanizada, à moradia, ao saneamento ambiental, à infra-estrutura e serviços públicos, ao transporte coletivo, à mobilidade e acessibilidade, ao emprego, trabalho e renda, à assistência social, bem como aos espaços públicos e ao patrimônio ambiental e cultural do Município;

II - função social da propriedade urbana, abrangendo:

a) habitação, especialmente habitação de interesse social;

b) atividades econômicas geradoras de emprego, trabalho e renda e que contribuam para o desenvolvimento da cidade;

c) utilização adequada dos recursos naturais disponíveis e preservação do meio ambiente;

d) preservação do patrimônio histórico, cultural e ambiental do Município.

e) preservação da seguridade.

III - sustentabilidade, que consiste no desenvolvimento local socialmente justo, ambientalmente equilibrado, economicamente viável, culturalmente diversificado, e política e institucionalmente democrática;

IV - gestão democrática, garantindo a participação da população em todas as decisões de interesse público por meio dos instrumentos de gestão democrática previstos na Lei Federal n ${ }^{\circ}$ 10.257, de 10 de julho de 2001 (Estatuto da Cidade).

Parágrafo único. Para garantir a função social da propriedade urbana, o uso e a ocupação do solo deverão ser compatíveis com a oferta de infra-estrutura, 
saneamento e serviços públicos e comunitários, e levar em conta o respeito ao direito de vizinhança, a segurança do patrimônio público e privado, a preservação e recuperação do ambiente natural e construído (BELÉM, 2008).

Podemos perceber que, no caso do município de Belém, existem delimitações teóricas do que seria a função social da cidade. A definição é ampla, abrangendo habitação, patrimônio público e ambiental. Em certos pontos, entretanto, ela é vaga, não proporcionando parâmetros mínimos para a aplicação do IPTU progressivo no tempo, de acordo com o seu art. 150. De todo modo, alguns cuidados precisam ser observados para que não se cometam injustiças com o fim de se buscar justiça social. Inicialmente, o instrumento deve se prestar à adequada coibição da especulação imobiliária. Ou seja, deve-se estabelecer parâmetros inteligentes e definir os valores apropriados para que seja possível caracterizar as condições de ociosidade e subutilização associados à especulação imobiliária. Além disso, deve-se considerar que um terreno não precisa estar inteiramente desocupado para que esteja em desacordo com a função social da propriedade. Dependendo do caso, pode-se ter hipótese de subutilização. Conforme vemos na imagem 01, grande parte da cidade, na chamada área de expansão (TRINDADE JÚNIOR, 2016), não exerce função social.

Contudo, a legislação belemense não possui uma aplicabilidade direta no mundo da vida. Trata-se de definições vagas e amplas sem uma característica de norma jurídica para que possa ser aplicada no dia a dia, e combater as desigualdades urbanas. Não obstante o texto legal tratar de "sustentabilidade", "gestão democrática" e "participação", ficou a cargo de normas específicas definir o que se entende por esses conceitos jurídicos que podem ter diversas interpretações.

$\mathrm{Na}$ análise da legislação, podemos perceber da necessidade de participação, tanto que consta em diversas esferas legislativas, mas, apesar disso, os efeitos dessa comunicação legal apenas formal são muito limitados, ou até ineficazes. O planejamento da aplicabilidade dessa lei pode ser muito melhor elaborado se forem ouvidas as pessoas e se chegue a um consenso baseado não na maior influência política, mas no melhor argumento. Mas, a formulação desse argumento será melhor feita com maior participação. É um círculo virtuoso que deve ser incentivado, e auxiliaria diretamente na formação do espaço urbano da cidade. 


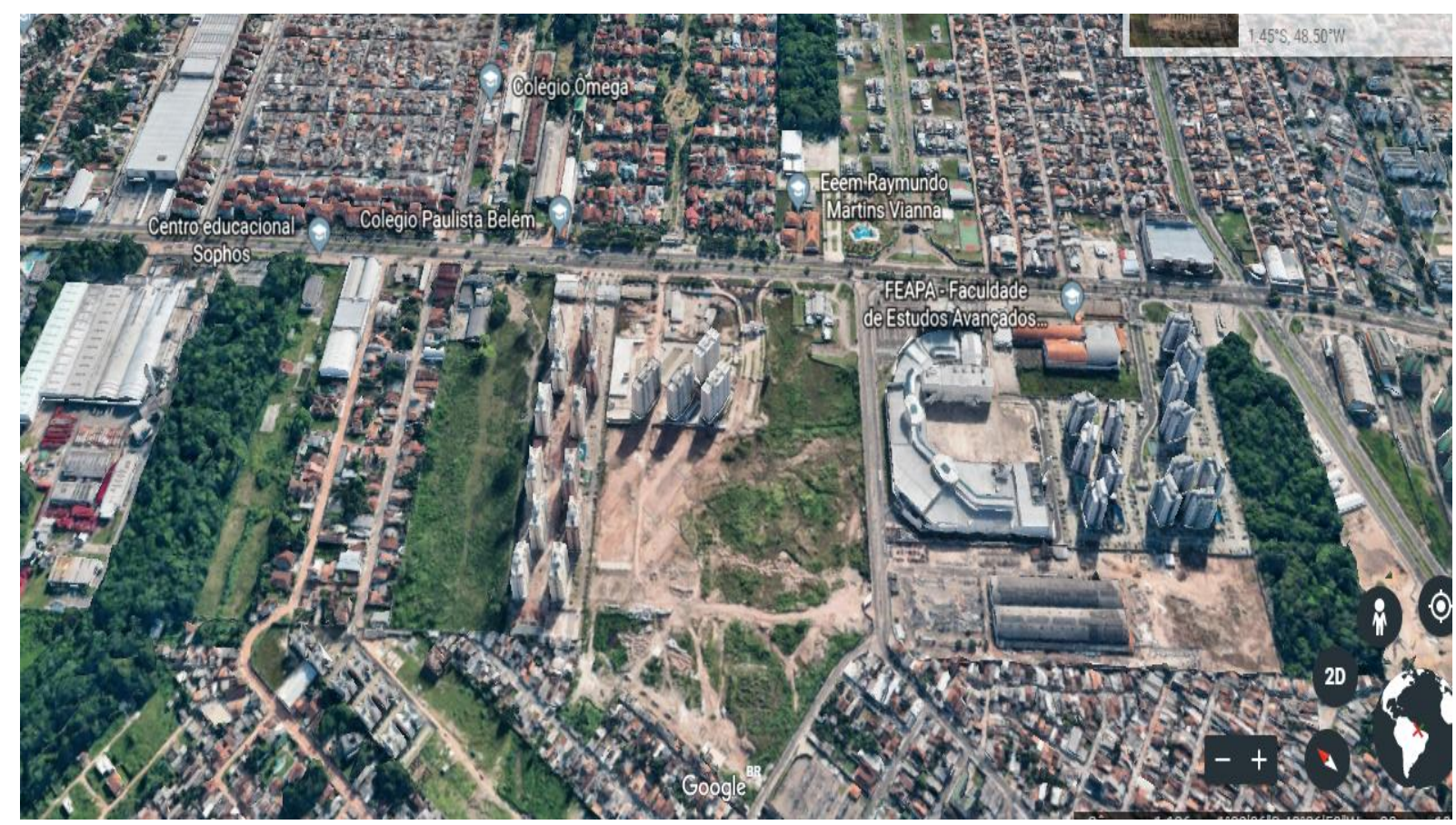

Fonte: https://earth.google.com/web/@-1.3540801,-

48.4534887,23.33487084a,1056.21073054d,35y,0h,45t,0r/data=ChUaEwoLL2cvMTIyOGZzajgYAiABKAIoAg

\section{CONSIDERAÇÕES FINAIS:}

A concepção habermasiana do agir comunicativo é fundamental para a elaboração de políticas públicas. Por meio do uso da linguagem voltada ao entendimento mútuo, permite-se ao falante expressar suas opiniões, comunicando-se com outros integrantes da comunidade linguística acerca de algo novo no mundo. Sem esses pressupostos, qualquer política pública, pode ser mascarada e apresentada por técnicos como a mais vantajosa, ainda que não cause efeitos práticos e careça de legitimidade. Essa falta de legitimidade transforma o direito não em um regulador de garantias, mas em um colonizador do mundo da vida.

O direito à cidade é um fundamento que deve ser aplicado necessariamente na evolução da sociedade urbana, buscando-se a igualdade, ele nos permite alcançar evolução. A problemática da cidade deve ser posta no centro da reflexão das sociedades contemporâneas, mesmo, ou talvez principalmente, nos espaços subutilizados. Não se imagina, entretanto, que a solução dos problemas do homem será encontrada nos frios códigos e legislações feitas por elites políticas. É contraproducente imaginar que a pobreza poderia ser eliminada sem modificações significativas na estrutura de produção, dos investimentos e do consumo.

Mas alguns instrumentos já postos na esfera legislativa podem e devem ser aplicados, pois se tratam de direitos fundamentais. Dentre eles, temos o IPTUPT, pelo meio do qual, em 
tese, é possível punir proprietários que não respeitem o que se entende por função social da propriedade, delimitado no plano diretor do município. Com isso, pode-se evitar especulações imobiliárias e subutilização de determinadas áreas urbanas, o que é importantíssimo para a justa distribuição de terras urbanas, e corrobora totalmente com o ideal de direito à cidade.

Sob esse aspecto, efetiva aplicação do IPTUPT pelos municípios pode ser uma valiosa ferramenta na tentativa de garantir-se maior justiça social na distribuição espacial da cidade, evitando-se vazios urbanos e auxiliando na luta contra a especulação imobiliária. Nesse ponto que é perceptível a necessidade de participação, tanto que consta em diversas esferas legislativas, mas, apesar disso, a participação de fato inexiste no que se refere ao IPTUPT. Não se buscou o melhor argumento para formular a política pública, mas sim a inexistência de argumento, a manutenção da especulação imobiliária em detrimento da função social.

É preciso, todavia, deixar claro um ponto, ainda que a participação seja necessária, seja um reflexo da responsabilização de todos pelo direito à cidade, não podemos esperar que ela solucione todos os problemas sociais. Na verdade, ela é um meio, e não a solução em si. E, como meio, deve ser estimulada em todos os espaços de convivência e níveis sociais para que ela possa trabalhar nos fins do planejamento urbano, seguindo a lógica do agir comunicativo, baseado no melhor argumento. Retomando à Nietzsche, se Deus está morto ou não, isso depende da fé individual de cada um. Mas, com a secularização do mundo, ele não é responsável pelo nosso mundo da vida. Os cidadãos vivem o mundo da vida e a eles deve ser delegada a responsabilização das decisões que lhes afetarão. Devemos entender que, na nossa história, os cidadãos devem ser os atores principais e os narradores.

\section{REFERENCIAS}

ALEXY, R. Teoria dos direitos fundamentais. São Paulo: Malheiros, 2011.

BELÉM, Prefeitura Municipal. Lei municipal 8.655/2008, de 30 de julho de 2008. Dispõe sobre o Plano Diretor do Município de Belém, e dá outras providências. Disponível em: $<$ http://www.belem.pa.gov.br/planodiretor/Plano_diretor_atual/Lei_N865508 _plano_diretor.pdf $>$. Acesso em: 16 set. 2018.

BOBBIO, N. O positivismo jurídico: lições de filosofia do direito. São Paulo: Ícone, 1995. BECKER, A. Teoria feral do direito tributário. $3^{\mathrm{a}}$ ed. São Paulo: Lejus 2002. 
BRASIL. Vade Mecum Saraiva. São Paulo: Saraiva Educação, 2018.

CASTRO, I E. Geografia e política: território, escalas de ação e instituições. $6^{\text {a }}$ ed. Rio de Janeiro: Betrando Brasil, 2014.

CARRAZZA, R. A. Curso de direito constitucional tributário,19 ed. São Paulo: Malheiros, 2004.

HARVEY, David. Alternativas ao neoliberalismo e o direito à cidade. Novos cadernos NAEA, v. 12, n. 2, p.269-274, 2009.

Espaços de Esperança. São Paulo: Edições Loyola, 2013.

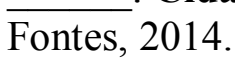

Cidades rebeldes: do direito à cidade à revolução urbana. São Paulo: Martins

KELSEN, Hans. Teoria Pura do Direito, 2a ed., v. II. Coimbra: Sucessor, 1962.

LEFEBVRE, Henri. O direito à cidade. São Paulo: Centauro, 2001.

MELLO, C. A. B. Curso de direito administrativo. São Paulo: Malheiros, 2009.

NIETZSCHE, F. Die fröhliche Wissenchaft. Altenmünster: Jazzybee Verlag Jürgens Beck.

SANTOS, M. Metamorfoses do espaço habitado: fundamentos teóricos e metodológicos da geografia. São Paulo: Editora da Universidade de São Paulo, 2014.

SARMENTO, D. Dignidade da pessoa humana: conteúdo, trajetórias e metodologia. 2. ed. Belo Horizonte: Fórum, 2016

SOUZA, M. L. Mudar a cidade: uma introdução crítica ao planejamento e à gestão urbanos. Rio de Janeiro: Bertrand Brasil, 2010.

SCHWEIZER, P-J., et al. Public participation for infrastructure planning in the context of the German "Energiewende", Utilities Policy, 2014.

THERBRN, G. Do marxismo ao pós-marxismo?. São Paulo: Boitempo, 2012.

TIPKE, K. Direito tributário: estudos em homenagem ao prof. Ruy Barbosa Nogueira. São Paulo: Saraiva, 1994.

TRINDADE JÚNIOR, S. C. Formação metropolitana de Belém. Belém: Paka-Tatu, 2016.

WEBER, Max. Economía y sociedad. México: Fondo de Cultura Económica, 1998. 